\title{
REDUCTION OF HYPOXIC PULMONARY VASOCONSTRICTION BY DIETHYL ETHER IN THE ISOLATED PERFUSED CAT LUNG: THE EFFECT OF ACIDOSIS AND ALKALOSIS
}

\author{
J. B. HuRTig, A.R. Tait, AND M.K. Sykes
}

Trie PULMONARY vasoconstrictor Response to alveolar hypoxia has been well documented. ${ }^{1-4}$ This is a vigorous response, ${ }^{5,6}$ and reduces blood flow to hypoxic lung units. Ventilation-perfusion imbalance and resulting venous admixture is thereby decreased and arterial oxygenation is improved. Any interference with this protective mechanism would therefore be detrimental.

Changes in acid-base conditons can alter the vasoconstrictor response to alveolar hypoxia. Acidosis has been shown to augment the response whereas alkalosis depresses or has little effect on it. ${ }^{7-11}$ It has been shown that diethyl ether, as well as other anaesthetic agents, depress hypoxic pulmonary vasoconstriction. ${ }^{12-15}$ In this laboratory diethyl ether was shown to diminsh the hypoxic pressor response in the isolated perfused cat lung under normal acid-base conditions. ${ }^{16}$ This study was therefore undertaken to document hypoxic pulmonary vasoconstriction during acidosis and alkalosis in this preparation and to determine whether diethyl ether would depress the hypoxic pressor response under these differing acid-base conditions.

\section{METHOD}

Isolated lung perfusion studies were undertaken in ten cats weighing between 2.0 and $6.0 \mathrm{~kg}$. Satisfactory experimental preparations with demonstration of hypoxic pulmonary vasoconstriction were obtained in eight animals. The animals were anaesthetized with intravenous pentobarbital $(30 \mathrm{mg} / \mathrm{kg})$ and a tracheostomy was immediately performed. The lungs were then ventilated with a constant volume second-stage paediatric ventilator, driven in the first instance by a Cape Ventilator (Figure 1(a)). The bellows of the second-stage attachment aspirated gases from a $\mathrm{T}$-piece reservoir connected to the fresh gas inflow. Diethyl ether was added to the circuit by a Blease Universal vaporizer, calibrated by a refractometer (Riken gas indicator interferometer type 18 ). The rate of ventilation was set at 20 breaths per minute and the tidal volume adjusted to keep the endtidal carbon dioxide concentration between 4 and 5 per cent. An end-expiratory pressure of 2 to $3 \mathrm{~cm} \mathrm{H}_{2} \mathrm{O}$ was applied when the chest was open to prevent atelectasis. Air was used as the ventilating gas until the lungs were isolated, at

J.B. Hurtig, M.D., F.R.C.P.(C), " A.R. Tait, B.Sc., and M.K. Sykes, M.B., B.Chir., F.F.A.R.C.S., Department of Anaesthetics, Royal Postgraduate Medical School, London, England

Present Address: Department of Anaesthesia, 4th Floor Link, Ottawa Civic Hospital and The University of Ottawa, 1053 Carling Avenue, Ottawa, Ontario, Canada, K1Y 4E9. 


\section{Ventilation Circuit}
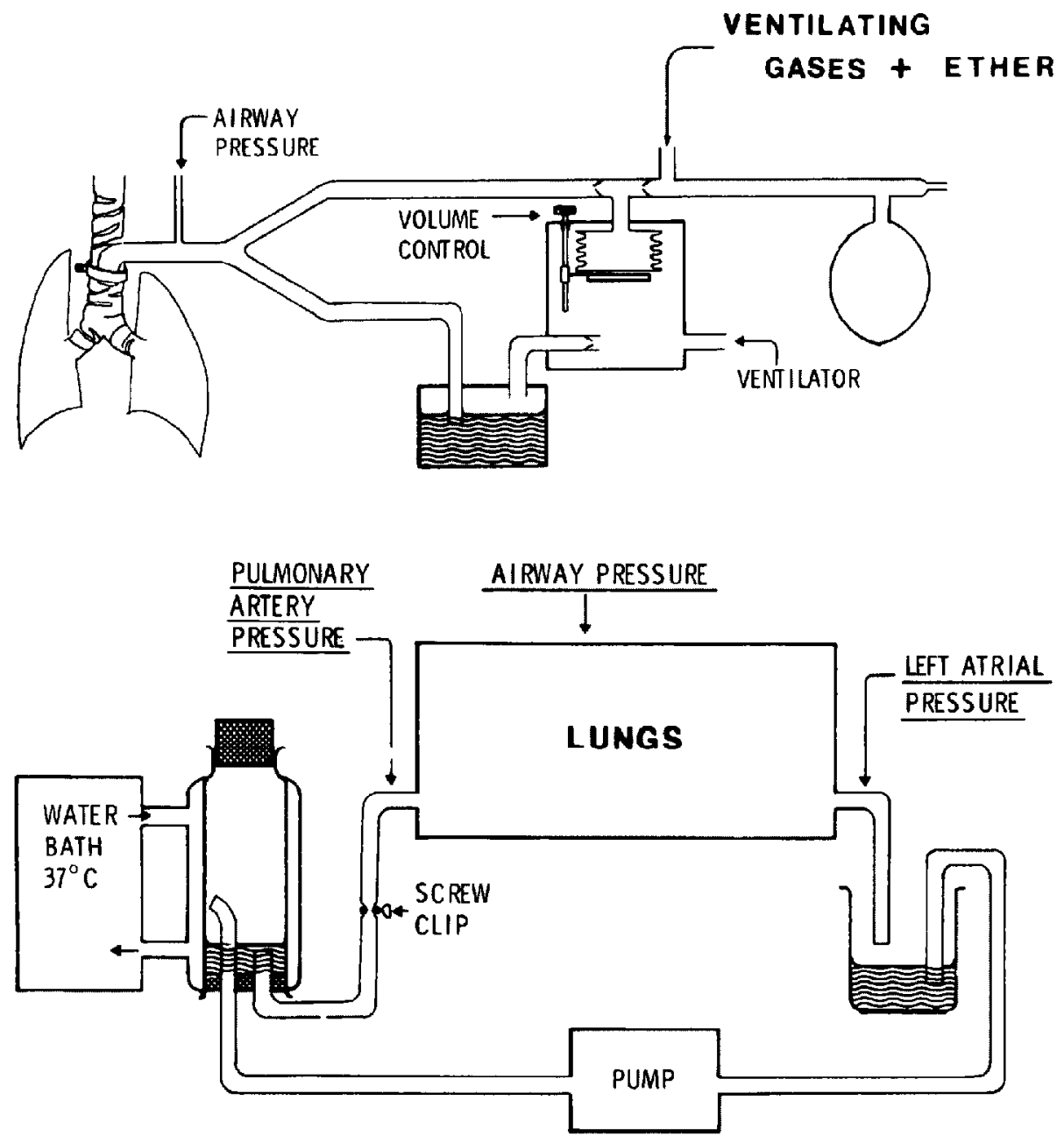

\section{Perfusion Circuit}

Frgure 1. Isolated perfused cat lung ventilation and perfusion circuit. (a) Ventilation Circuit, (b) Perfusion Circuit. 
which time 5 per cent carbon dioxide was added to maintain a normal $\mathrm{PCO}_{2}$ during isolated lung perfusion.

The heart was then exposed through a median sternotomy and a $3 \mathrm{~mm}$ i.d. cannula was inserted into the right atrium. Heparin $300 \mathrm{units} / \mathrm{kg}$ was injected through the cannula and allowed to circulate.

The animal was then rapidly exsanguinated into the perfusion circuit reservoir. In the smaller cats 10 to $20 \mathrm{ml}$ of dextran (dextran 110 injection B.P. in 0.9 per cent sodium chloride) was added to increase the volume of perfusate to a workable level. The animal was then prepared for connection to the perfusion circuit (Figure $1(b)$ ). The right atrial cannula was removed and the pulmonary artery and aorta were cross-clamped just proximal to the pulmonary artery bifurcation in order to prevent air emboli from entering the lungs. The pulmonary artery was then cannulated through the wall of the right ventricle. A second cannula was inserted into the left atrium through the left ventricular wall. These cannulae were both firmly anchored. All air was aspirated from the pulmonary artery cannula and the line was connected to the perfusion circuit. The left atrial cannula was then led into a drainage reservoir which was connected in turn to an occlusive roller pump, previously flow-calibrated with blood. The pulsatile flow from the roller pump was smoothed by the air in the heat exchanger as well as by a screw clamp on the line leading to the pulmonary artery cannula. Blood was therefore drained from the lungs through the left atrial cannula and pumped from the left atrial reservoir through a heat exchanger with a water bath temperature of $37^{\circ} \mathrm{C}$, and back into the lungs through the pulmonary artery (Figure $1(\mathrm{~b})$ ).

Ischaemia time was noted and the perfusion was commenced slowly. The flow rate was increased to produce a mean pulmonary artery pressure in the range of 15 to $25 \mathrm{~mm} \mathrm{Hg}$, with the mean left atrial pressure set between 3 and $5 \mathrm{~mm} \mathrm{Hg}$. When the perfusion was established the lungs were ventilated with 5 per cent carbon dioxide in air, and the $\mathrm{pH}$ of the perfusate was measured. Pulmonary artery, left atrial, and airway pressures were measured continuously utilizing Consolidated Dynamics transducers and Devices Ltd. heated-stylus recorders. Immediately after commencing perfusion the $\mathrm{pH}$ of the perfusate was invariably acidotic ( $\mathrm{pH}<7.25)$. Under these conditions the animal was ventilated with a mixture of 3 per cent oxygen, 5 per cent carbon dioxide and nitrogen for three minutes to assess the change in pulmonary artery pressure in response to alveolar hypoxia. After reintroduction of 5 per cent carbon dioxide in air and after pulmonary artery pressure had returned to baseline levels, sodium bicarbonate was added, until the $\mathrm{pH}$ of the perfusate became normal ( $\mathrm{pH} 7.30-7.45$ ). The animal was then ventilated for three minutes with 3 per cent oxygen, 5 per cent carbon dioxide and nitrogen to test the hypoxic pressor response under normal acid-base conditions. The animal was then ventilated with 5 per cent carbon dioxide in air and sodium bicarbonate was added to render the perfusate alkalotic $(\mathrm{pH}>7.50)$. Under these conditions the hypoxic mixture was reintroduced for three minutes and the changes in pressure were recorded. The mixture of 5 per cent carbon dioxide in air was then substituted and diethyl ether ( 2 per cent) was added for ten minutes. Lactic acid was then added to the perfusate until the $\mathrm{pH}$ was decreased below 7.25. With ether administration continuing, a three-minute exposure to the hypoxic mixture followed. Sodium bicarbonate was then added in 
stages and the hypoxic mixture was introduced for three-minute exposure in the presence of diethyl ether during conditions of both normal $\mathrm{pH}$ and metabolic alkalosis.

The diethyl ether was then washed out for a minimum of 30 minutes, until a vigorous hypoxic pressor response had returned. The perfusate was then rendered acidotic with lactic acid and the hypoxic pressor response was tested. Finally, sodium bicarbonate was added and the hypoxic pressor response was tested under normal and alkalotic conditions. The perfusion was then terminated. In three animals the sequence of acid-base conditions was changed to assess the possibility that the order of the protocol might affect the results.

At each stage of the experiment, during both normoxia and hypoxia the following calculations were made:

1.

$$
\begin{aligned}
\text { PVR } & =\left(\mathrm{P}_{\overline{\mathrm{IA}}}-\mathrm{P}_{\overline{\mathrm{LA}}} \times 100 / \dot{\mathrm{Q}}(\mathrm{mm} \mathrm{Hg} / 100 \mathrm{ml} / \mathrm{min})\right. \\
\text { Where } \mathrm{P}_{\overline{\mathrm{PA}}} & =\text { mean pulmonary artery pressure }(\mathrm{mm} \mathrm{Hg}), \\
\mathrm{P}_{\overline{\mathrm{LA}}} & =\text { mean left atrial pressure }(\mathrm{mm} \mathrm{Hg}), \\
\text { and } \dot{\mathrm{Q}} & =\text { pulmonary blood flow }(\mathrm{ml} / \mathrm{min}) .
\end{aligned}
$$

2. Increase and percentage increase in pulmonary artery pressure over baseline level in response to alveolar hypoxia.

The control hypoxic pressor responses during acidosis, alkalosis and at normal $\mathrm{pH}$ (as measured by percentage increases in pulmonary artery pressure and values for pulmonary vascular resistance) were then compared statistically with the hypoxic pressor responses under these conditions during administration of diethyl ether. No measurement in the presence of diethyl ether was included in the results unless the hypoxic pressor response could be demonstrated again after wash-out of the ether.

\section{REsULTS}

There were eight successful perfusions in which hypoxic pulmonary vasoconstriction was demonstrated. Ischaemia time (from completion of exsanguination to onset of perfusion) averaged 9.0 minutes, and total perfusion time 199.5 minutes. Pulmonary blood flow averaged $52.4 \mathrm{ml} / \mathrm{kg}$ and mean left atrial pressure $3.7 \mathrm{~mm} \mathrm{Hg}$.

Percentage changes in mean pulmonary artery pressure during the hypoxia through the course of the experiment are shown in Table I and Figure 2. A marked increase in pulmonary artery pressure indicating a vigorous hypoxic pressor response was seen in this preparation during acidosis, alkalosis and at normal $\mathrm{pH}$. When diethyl ether ( 2 per cent) was added, the hypoxic pressor response was significantly reduced in all three acid-base states. Wash-out of the diethyl ether resulted in the return of a marked hypoxic pressor response, seen again during all three acid-base situations. There were no significant differences in the percentage increase in pulmonary artery pressure during acidosis, as opposed to normal $\mathrm{pH}$ or alkalosis, either in the control states or in the presence of diethyl ether. A typical response is illustrated in Figure 3. The hypoxic stimulus provoked a brisk pressor response, no matter what the $\mathrm{pH}$ of the perfusate. Addition of diethyl ether blunted 
TABLE I

Hypoxic Pressor Response

Absolute and percentage increases in mean pulmonary artery pressure $(\mathrm{P}-\overline{\mathrm{PA}})(\mathrm{mm} \mathrm{Hg})$ in eight cats in response to hypoxia, during acidosis, normal $\mathrm{pH}_{1}$ and alkalosis without $(\mathrm{C}=\mathrm{control})$ and in the presence of diethyl ether (DE)

\begin{tabular}{|c|c|c|c|c|c|c|c|c|c|c|}
\hline \multirow[b]{2}{*}{$\mathrm{pH}$} & \multicolumn{4}{|c|}{ Control 1} & \multicolumn{3}{|c|}{$2 \%$ diethyl ether } & \multicolumn{3}{|c|}{ Control 2} \\
\hline & $\mathrm{AC}$ & $\vec{N}$ & $\mathrm{~N}$ & ALK & $\mathrm{AC}$ & $\mathrm{N}$ & ALK & $\mathrm{AC}$ & $\mathrm{N}$ & ALK \\
\hline \multirow{2}{*}{$\begin{array}{c}\uparrow \mathrm{P}_{\overline{\mathrm{PA}}} \\
\mathrm{m} \\
\% \uparrow \mathrm{P}_{\overline{\mathrm{PA}}} \\
\mathrm{m}_{(\mathrm{SD})}\end{array}$} & 9.0 & & .3 & 8.4 & 1.2 & 1.6 & 1.3 & 8,4 & 9.4 & 9.1 \\
\hline & $\begin{array}{c}51.4 \\
(13.6)\end{array}$ & & $\begin{array}{l}.6 \\
.1)\end{array}$ & $\begin{array}{c}57.0 \\
(14.9)\end{array}$ & $\begin{array}{c}7.4 \\
(4.8)\end{array}$ & $\begin{array}{c}9.8 \\
(6.5)\end{array}$ & $\begin{array}{c}7.7 \\
(5.0)\end{array}$ & $\begin{array}{c}53.2 \\
(30.8)\end{array}$ & $\begin{array}{c}66.4 \\
(34.2)\end{array}$ & $\begin{array}{c}60.9 \\
(26.3)\end{array}$ \\
\hline \multirow{2}{*}{ Statistics } & \multicolumn{3}{|c|}{$\begin{array}{l}\text { Acidosis } \\
\text { Normal pH } \\
\text { Alkalosis }\end{array}$} & \multicolumn{2}{|c|}{$\begin{array}{l}\text { Cl vs DE } \mathrm{p}<0.001 \\
\mathrm{Cl} \text { vs } \mathrm{DE} \mathrm{p}<0.001 \\
\mathrm{Cl} \text { vs } \mathrm{DE} \mathrm{p}<0.001\end{array}$} & & \multicolumn{3}{|c|}{$\begin{array}{l}\text { C2 vs DE } \mathrm{p}<0.01 \\
\mathrm{C} 2 \text { vs DE } \mathrm{p}<0.01 \\
\mathrm{C} 2 \text { vs } \mathrm{DE} \mathrm{p}<0.001\end{array}$} & \\
\hline & \multicolumn{2}{|c|}{$\begin{array}{l}\text { Control } 1 \\
\text { Diethyl ether } \\
\text { Control } 2\end{array}$} & \multicolumn{2}{|c|}{$\begin{array}{l}A C \text { vs } N \text { NS } \\
A C \text { vs N NS } \\
A C \text { vs } N \text { NS }\end{array}$} & \multicolumn{3}{|c|}{$\begin{array}{l}\mathrm{N} \text { vs ALK NS } \\
\mathrm{N} \text { vs ALK NS } \\
\mathrm{N} \text { vs ALK NS }\end{array}$} & \multicolumn{2}{|c|}{$\begin{array}{l}\text { AC vs ALK NS } \\
A C \text { vs ALK NS } \\
\text { AC vs ALK NS }\end{array}$} & \\
\hline
\end{tabular}

$\mathrm{AC}=$ Acidosis. $\quad \mathrm{ALK}=$ Alkalosis. $\quad \mathrm{NS}=$ No significant difference. $\mathrm{N}=$ Normal $\mathrm{pH}$

Hypoxic Pressor Response

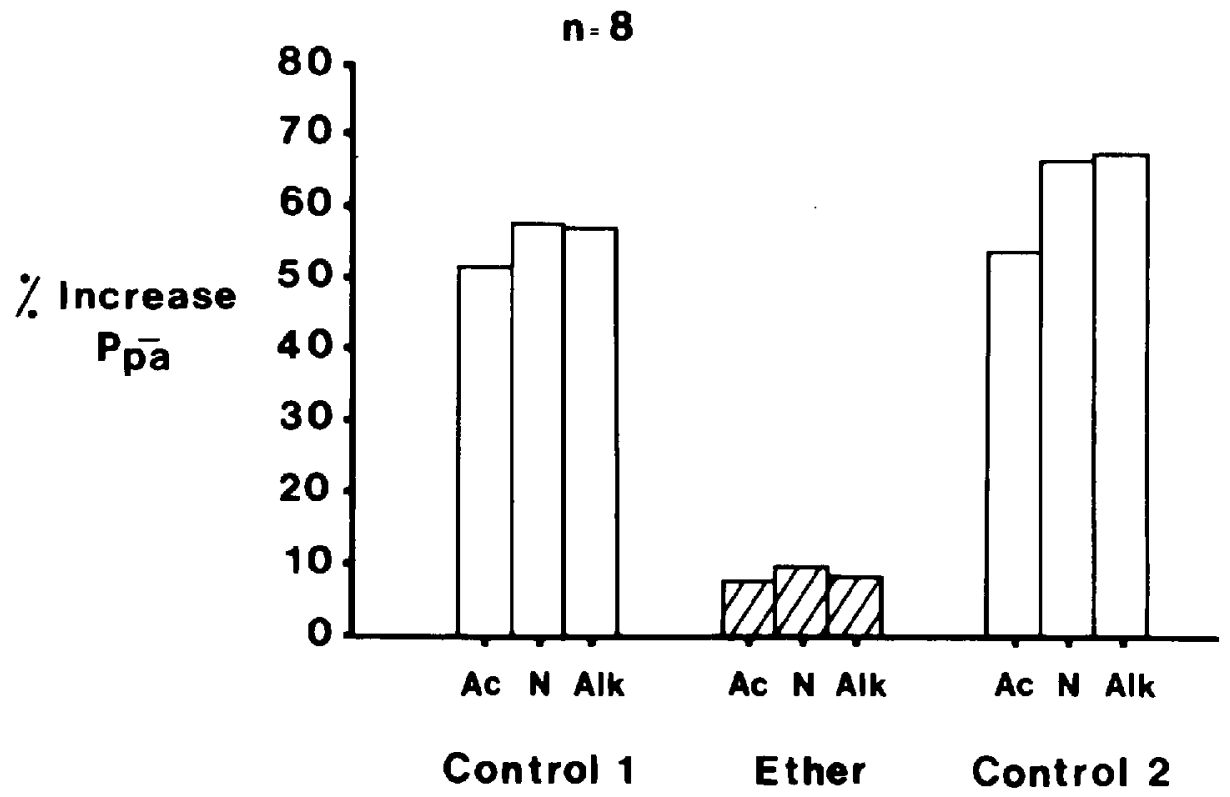

Figuhe 2. Hypoxic pressor response. A comparison of percentage increases in mean pulmonary artery pressure $\left(P_{\bar{P} \wedge}\right)(\mathrm{mm} \mathrm{Hg})$ in response to 3 per cent oxygen inhalation during acidosis (AC), normal $\mathrm{pH}(\mathrm{N})$ and alkalosis (ALK), without (control 1 and control 2 ), and in the presence of diethyl ether ( $n=$ number of observations). 


\section{Perfusion Circuit}
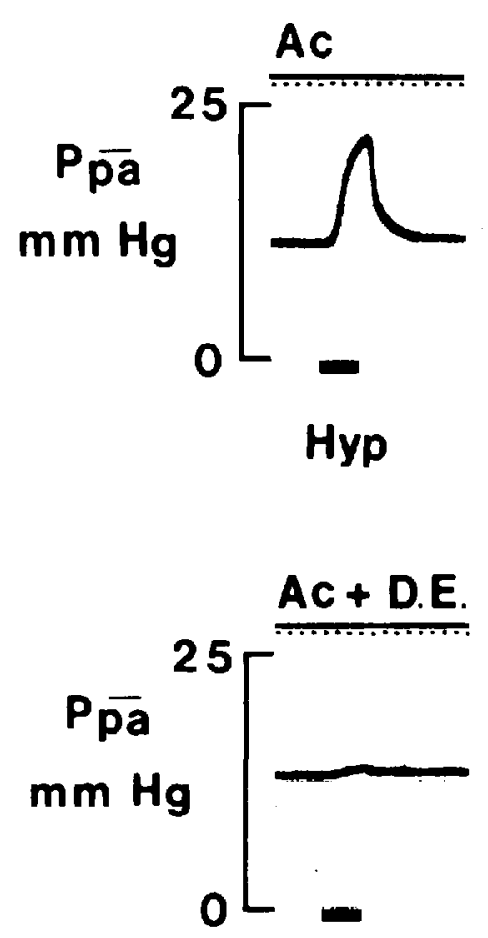

Hyp

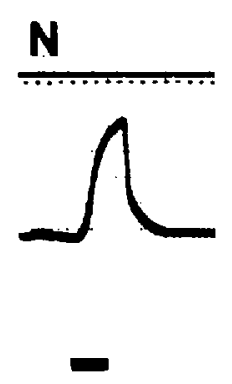

Hyp

N + D.E.

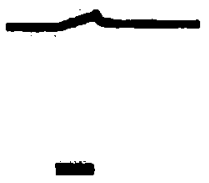

Hyp

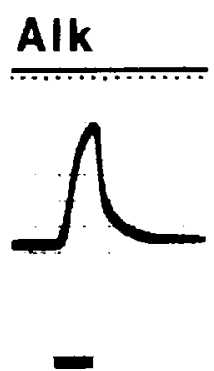

Hyp

Figune 3. Hypoxic pressor response. A typical pulmonary pressor response to 3 per cent oxygen inhalation is seen in the top row of traces during acidosis (AC), nomal pH (N), and alkalosis (ALK). These brisk responses compare to much reduced responses seen in the lower three traces on exposure to 3 per cent oxygen in the presence of diethyl ether (DE) ( $\mathrm{P}_{\overline{\mathrm{A}}}-$ mean pulmonary artery pressure, hyp - hypoxic stimulus).

the response, which returned after the ether was washed out. The three experiments in which the sequence of acid-base conditions was changed showed depression of hypoxic pulmonary vasoconstriction at all $\mathrm{pH}$ levels in the presence of diethyl ether similar to the other experimental animals.

Comparison of pulmonary vascular resistances in the presence of hypoxia, during acidosis, normal $\mathrm{pH}$, and alkalosis both without and in the presence of diethyl ether is shown in Table II and Figure 4. Diethyl ether caused a significant reduction in hypoxic vasoconstriction as measured by pulmonary vascular resistance during all acid-base states, the responses returning to control levels when ether had been withdrawn.

Changes in baseline pulmonary vascular resistance during normoxia through the course of the experiment are shown in Table III and Figure 5. The addition of 
TABLE II

HyPoXIC PRESSOR RESPONSE

Pulmonary vascular resistance (PVR) ( $\mathrm{mm} \mathrm{Hg} / 100 \mathrm{ml} / \mathrm{min}$ ) in response to hypoxia in eight cats during acidosis, normal $\mathrm{pH}$, and alkalosis, without $(\mathrm{C}=$ control $)$ and in the presence of diethyl ether (DE)

\begin{tabular}{|c|c|c|c|c|c|c|c|c|c|}
\hline \multirow[b]{2}{*}{$\mathrm{pH}$} & \multicolumn{3}{|c|}{ Control 1} & \multicolumn{3}{|c|}{$2 \%$ diethyl ether } & \multicolumn{3}{|c|}{ Control 2} \\
\hline & $\mathrm{AC}$ & $\mathrm{N}$ & ALK & $\mathrm{AC}$ & $N$ & ALK & $A C$ & $\mathrm{~N}$ & ALK \\
\hline $\begin{array}{c}\text { PVR } \\
\text { m } \\
(\mathrm{SD})\end{array}$ & $\begin{array}{l}16.2 \\
(6.6)\end{array}$ & $\begin{array}{l}15.3 \\
(5.9)\end{array}$ & $\begin{array}{l}13.9 \\
(5.2)\end{array}$ & $\begin{array}{c}3.9 \\
(3.9)\end{array}$ & $\begin{array}{c}9.5 \\
(4.4)\end{array}$ & $\begin{array}{c}9.3 \\
(3.8)\end{array}$ & $\begin{array}{l}14.7 \\
(5.1)\end{array}$ & $\begin{array}{c}14.4 \\
(4.2)\end{array}$ & $\begin{array}{l}13.4 \\
(4.3)\end{array}$ \\
\hline Statistics & $\begin{array}{l}\text { Acidosis } \\
\text { Normal pH } \\
\text { Alkalosis }\end{array}$ & $\begin{array}{l}\mathrm{CL} \\
\mathrm{C} 1 \\
\mathrm{C} 1\end{array}$ & $\begin{array}{l}\text { Is DE } p \\
\text { s DE } \\
\text { is DE } \mathrm{p}\end{array}$ & $\begin{array}{l}0.001 \\
0.001 \\
0.002\end{array}$ & & $\begin{array}{l}\mathrm{C} 2 \text { vs } D \\
\mathrm{C} 2 \text { vs } \mathrm{D} \\
\mathrm{C} 2 \text { vs } \mathrm{D}\end{array}$ & $\begin{array}{l}p<0.0 \\
p<0.0 \\
p<0.0\end{array}$ & & \\
\hline
\end{tabular}

$\mathrm{AC}=$ Acidosis. $\mathrm{N}=$ Norma $\mathrm{pH} . \quad \mathrm{ALK}=$ Alkalosis.

\section{PVR ( $\mathrm{mm} \mathrm{Hg} / 100 \mathrm{ml} / \mathrm{min})$ during Hypoxia}

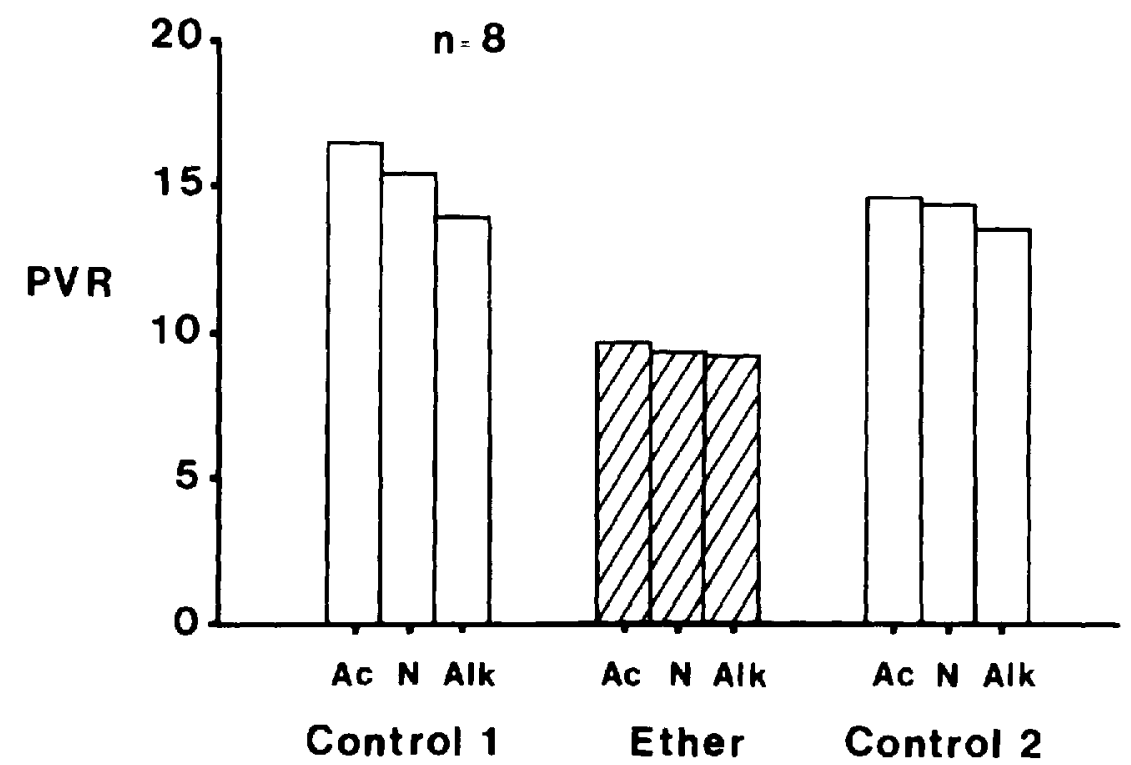

Figure 4. Hypoxic pressor response. A comparison of pulmonary vascular resistances (PVR) ( $\mathrm{mm} \mathrm{Hg} / 100 \mathrm{ml} / \mathrm{min}$ ) in response to 3 per cent oxygen inhalation during acidosis (AC), normal $\mathrm{pH}(\mathrm{N})$, and alkalosis (ALK), without (control 1 and control 2) and in the presence of diethyl ether ( $n=$ number of observations).

diethyl ether failed to cause significant increases in pulmonary vascular resistance. In the control situations, as well as during diethyl ether administration, baseline pulmonary vascular resistance often dropped as the perfusate was made more alkalotic. 
TABLE III

Baseline Pulmonary Vasctlar Resistance

Pulmanary vascular resistance (PVR) $(\mathrm{mm} \mathrm{Hg} / 100 \mathrm{ml} / \mathrm{min}$ ) in eight cats under normoxic con. ditions during acidosis, normal $\mathrm{pH}_{1}$ and alkalosis without $(\mathrm{C}=$ control), and in the presence of diethyl ether (DE)

\begin{tabular}{|c|c|c|c|c|c|c|c|c|c|}
\hline \multirow[b]{2}{*}{$\mathrm{pH}$} & \multicolumn{3}{|c|}{ Control 1) } & \multicolumn{3}{|c|}{$2 \%$ diethyl ether } & \multicolumn{3}{|c|}{ Control 2} \\
\hline & $A C$ & $\mathrm{~N}$ & ALK & $A C$ & $\mathrm{~N}$ & ALK & $\mathrm{AC}$ & $\mathrm{N}$ & ALK \\
\hline $\begin{array}{l}\mathrm{PVR} \\
\mathrm{m} \\
(\mathrm{SD})\end{array}$ & $\begin{array}{c}9.9 \\
(4.7)\end{array}$ & $\begin{array}{l}8.8 \\
(3.7)\end{array}$ & $\begin{array}{c}7.9 \\
(3.5)\end{array}$ & $\begin{array}{c}8.7 \\
(3.5)\end{array}$ & $\begin{array}{c}8.2 \\
(3.3)\end{array}$ & $\begin{array}{c}8.1 \\
(3.3)\end{array}$ & $\begin{array}{c}9.0 \\
(3.5)\end{array}$ & $\begin{array}{c}7.7 \\
(3.7)\end{array}$ & $\begin{array}{c}7.2 \\
(2.6)\end{array}$ \\
\hline \multirow{2}{*}{ Statistics } & $\begin{array}{l}\text { Acidosis } \\
\text { Normal pH } \\
\text { Alkalosis }\end{array}$ & \multicolumn{3}{|c|}{$\begin{array}{l}\text { C1 vs DE NS } \\
C 1 \text { vs DE NS } \\
C 1 \text { vs DE NS }\end{array}$} & \multicolumn{5}{|c|}{$\begin{array}{l}\text { C2 vs DE NS } \\
\text { C2 vs DE NS } \\
\text { C2 vs DE } \mathrm{p}<0.05\end{array}$} \\
\hline & $\begin{array}{l}\text { Control } 1 \\
\text { Diethyl ether } \\
\text { Control } 2\end{array}$ & \multicolumn{3}{|c|}{$\begin{array}{l}A C \text { vs } N \text { NS } \\
A C \text { vs } N p<0.05 \\
A C \text { vs } N \text { p }<0.05\end{array}$} & \multicolumn{2}{|c|}{$\begin{array}{l}N \text { vs ALK NS } \\
N \text { vs ALK p< } 0.01 \\
N \text { vs ALK NS }\end{array}$} & \multicolumn{3}{|c|}{$\begin{array}{l}\text { AC vs ALK NS } \\
\text { AC vs ALK } p<0.05 \\
\text { AC vs ALK } p<0.05\end{array}$} \\
\hline
\end{tabular}

$\mathrm{AC}=$ Acidosis. $\mathrm{N}=$ Normal $\mathrm{pH} . \quad \mathrm{ALK}=$ Alkalosis. $\mathrm{NS}=$ No significant difference.

\section{Discussion}

In this study, hypoxic pulmonary vasoconstriction was demonstrated during conditions of normal $\mathrm{pH}$, acidosis, and alkalosis. When 2 per cent diethyl ether was added, there was a marked reduction in the hypoxic pressor response in all three acid-base states. One can therefore conclude that, in this preparation, diethyl ether reduces hypoxic pulmonary vasoconstriction irrespective of $\mathrm{pH}$ of the pulmonary blood fow. While this experimental model is quite artificial in comparison with the intact animal or man, it offers certain advantages in the study of pulmonary vascular reactivity.

Cardiovascular, respiratory, and neurohumoral factors can markedly affect pulmonary vascular resistance. ${ }^{17}$ Among important cardiovascular variables are changes in cardiac output and left atrial pressure; and an increase in left atrial pressure has also been noted to decrease or abolish hypoxic pulmonary vasoconstriction. ${ }^{18}$ In this study, the pulmonary blood flow was held constant by controlling roller pump flow and left atrial pressure was controlled and held constant by manipulating the blood level in the left atrial reservoir. Pulmonary vascular resistance may be affected by changes in alveolar pressure if this exceeds left atrial pressure. ${ }^{10}$ In this study, mean airway pressure was kept constant and below left atrial pressure. Nervous and humoral factors can affect pulmonary vascular resistance, ${ }^{20-23}$ as well as hypoxic pulmonary vasoconstriction. ${ }^{24,25}$ In the isolated lung preparation, systemic humoral factors are not a consideration, and obliteration of bronchial blood flow has been noted to interrupt sympathetic nerve supply to the lungs. ${ }^{26}$ As a result of control of all these variables, changes in the pulmonary artery pressure could be directly interpreted as changes in pulmonary vascular resistance, indicating an increase in the tone of the pulmonary vasculature in response to the hypoxic stimulus.

The equally marked hypoxic pressor response seen in this study during acidosis, 


\section{PVR $\mathrm{mm} \mathrm{Hg} / 100 \mathrm{ml} / \mathrm{min}$ under normoxic conditions}

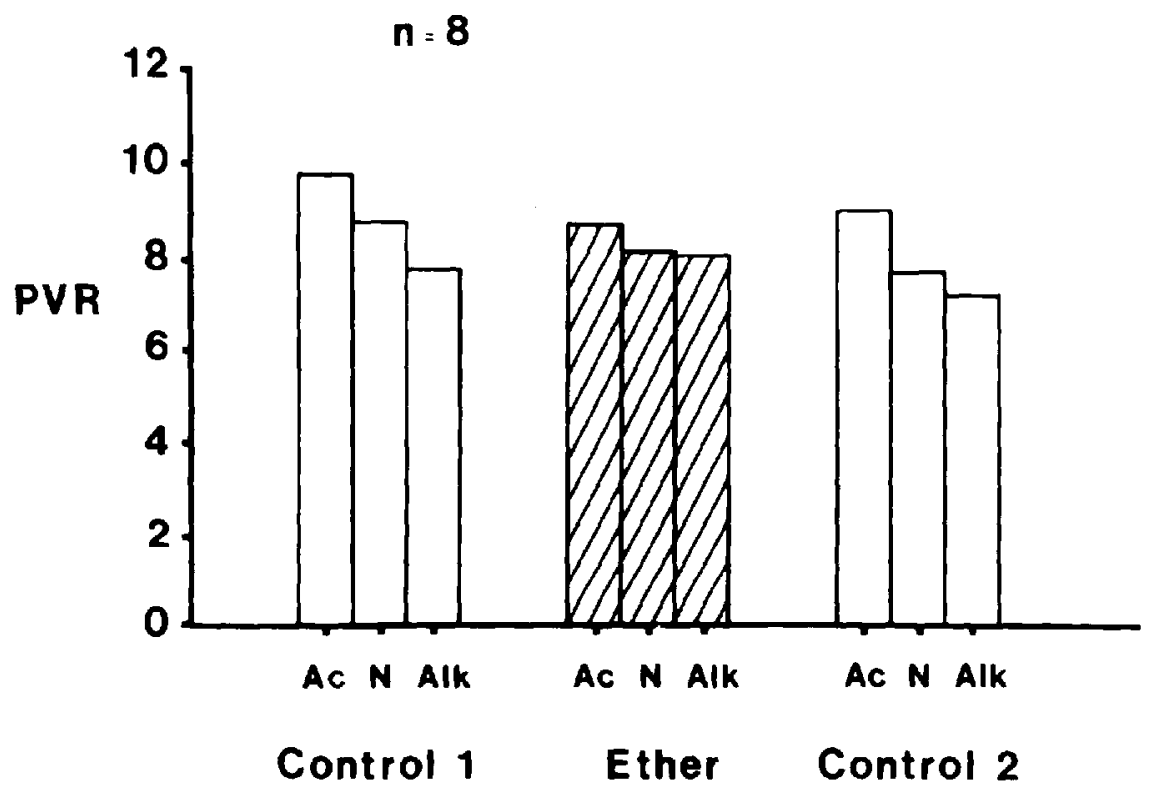

Figure 5. Changes in pulmonary vascular resistance (PVR) $(\mathrm{mm} \mathrm{Hg} / 100 \mathrm{ml} / \mathrm{min})$ through the course of the experiment during normoxic conditions ( $\mathrm{n}=$ number of observations, acidosis - AC, alkalosis - ALK, nomal pH - N).

normal $\mathrm{pH}$, and alkalosis is interesting in the light of previous findings. Acidosis, whether due to hypercapnia or to increased $\mathrm{H}^{+}$or other acid, has been shown to augment the pulmonary pressor response to alveolar hypoxia, whereas alkalosis usually diminishes the response. ${ }^{i-11}$ Further work has shown that potentiation of the hypoxic pressor response during hypercapneic acidosis may be due to the effect of increased $\mathrm{PCO}_{2}$ and not an increase in $\mathrm{H}^{+}$concentration. ${ }^{27}$ That study also suggested that an increase or a decrease in $\mathrm{H}^{+}$concentration when $\mathrm{PCO}_{2}$ is normal can cause depression of the hypoxic pressor response. Other workers, however, maintain that carbon dioxide itself is a pulmonary vasodilator, but that this action is usually masked by the strong vasoconstrictor action of carbonic acid. ${ }^{28,29}$ These variations may be due to differences in species or experimental models. Alkalosis, on the other hand, whether due to decreased $\mathrm{H}^{+}$concentration or decreased $\mathrm{PCO}_{2}$, depresses or has little effect on the hypoxic pulmonary pressor response. . $^{7,9,27}$

In this preparation a brisk response to hypoxia was noted throughout the control measurements, with metabolic acidosis or alkalosis causing little increase or decrease in the vigour of the response. The findings might support the work of Malik and Kidd, ${ }^{27}$ who emphasize the importance of excess carbon dioxide in the aug- 
mentation of the hypoxic pressor response during acidosis. However, manipulation of $\mathrm{H}^{+}$concentration in either direction caused a decrease in hypoxic pulmonary vasoconstriction in their preparation. The stability of the response in this study may merely reflect its vigour and this might further emphasize the potency of diethyl ether as a depressant of the hypoxic pressor response. It may also be that the $\mathrm{pH}$ values studied were not extreme enough during acidosis $(\mathrm{pH} 7.15$ 7.25) and alkalosis ( $\mathrm{pH} 7.50-7.60)$ to cause significant change in the response.

Previous work in isolated lung perfusion studies, ${ }^{16}$ intact animals, ${ }^{12-14}$ and man, ${ }^{15}$ demonstrates that inhalation anaesthetics, diethyl ether among them, depress hypoxic pulmonary vasoconstriction. The hypoxic pulmonary pressor response has been well demonstrated in man, ${ }^{1-4}$ reducing ventilation-perfusion imbalance by diverting pulmonary blood flow from hypoxic to better oxygenated lung units. As a result, venous admixture may be reduced and arterial oxygenation improved. If anaesthetic agents impair this homeostatic mechanism, this may be a further cause of the well documented arterial hypoxaemia seen during general anaesthesia. ${ }^{30,31}$

Changes in acid-base status, whether due to respiratory or metabolic causes, are not uncommon during anaesthesia, especially in seriously ill patients. In this experimental model, diethyl ether was shown to markedly impair hypoxic pulmonary vasoconstriction during conditions of acidosis, alkalosis, and at normal $\mathrm{pH}$. The pressor response to alveolar hypoxia would be a vital compensatory mechanism in any acutely ill patient, especially when further derangements of metabolic or ventilatory function were present. These patients might then be subject to further deterioration in the efficiency of arterial oxygenation when subjected to an anaesthetic agent such as diethyl ether. Accordingly, further work to document hypoxic vasoconstriction under abnormal acid-base conditions in both the awake state and during anaesthesia in intact animals and man would be in order. In addition, studies quantitatively correlating loss of hypoxic pulmonary vasoconstriction with a deterioration in arterial oxygenation would be useful to increase our understanding of this problem.

\section{SUMmany}

Hypoxic pulmonary vasoconstriction is a protective mechanism diverting pulmonary blood flow away from hypoxic areas toward more optimally oxygenated lung units. Venous admixture is reduced and arterial oxygenation improved. Hypoxic pulmonary vasoconstriction was demonstrated during acidosis, alkalosis and normal $\mathrm{pH}$ in the isolated perfused cat lung under conditions of constant flow and constant left atrial and airway pressures. Two per cent diethyl ether markedly reduced hypoxic vasoconstriction under all acid-base conditions, the hypoxic pressor response returning after wash-out of diethyl ether. Modification of hypoxic pulmonary vasoconstriction during acid-base disturbances and possible implications of concurrent anaesthetic administration are discussed.

\section{RÉSUMÉ}

La vasoconstriction pulmonaire secondaire à l'hypoxie représente un mécanisme protecteur permettant au flot sanguin pulmonaire d'éviter les régions hypoxiques 
et d'être dirigé vers les régions mieux ventilées. Le shunt est ainsi diminué et l'oxygénation artérielle améliorée.

La perfusion à débit constant de poumons de chats isolés, avec maintien constant de la pression auriculaire gauche et de la pression des voies aériennes, a démontré la persistance de ce réflexe à $\mathrm{pH}$ alcalin, normal ou acidotique.

L'administration d'éther à 2 pour cent a diminué cette réponse de façon marquée, indépendamment des variations de $\mathrm{pH}$, avec retour du réflexe après arrêt de l'administration et diminution de l'éther.

\section{ACKNOWLEDGMENT}

Dr. J.B. Hurtig was supported by an Ontario (Canada) Department of Health Research Fellowship.

\section{REFERENCES}

1. Himmelstein, A., Harris, P., Fritis, H.W., \& Counnand, A. Effect of severe unilateral hypoxia on the partition of the pulmonary blood flow in man. J. Thorac. Surg. 36: 369 (1958).

2. Defares, J.G., Lundin, G., Arborelius, M., Stromblad, R., \& Svanberc, L. Effect of unilateral hypoxia on pulmonary blood flow distribution in normal subjects. J. Appl. Physiol. 15: 169 (1960)

3. FowtER, K.T. \& READ, J. Effect of alveolar hypoxia on zonal distribution of pulmonary blood flow. J. Appl. Physiol. 18: 244 (1963).

4. Lopez-Majano, V., Wagnter, H.N., Twining, R.H., Tow, D.E., \& Chernick, V. Effect of regional hypoxin on the distribution of pulmonary blood flow in man. Circulat. Res. 18: $550(1966)$.

5. Amionelius, M. \& LiLja, B. Effects of hypoxia on the distribution of pulmonary blood flow in man. Bull. Physiopathol. Resp. (Nancy) 11: $131 \mathrm{P}$ (1975).

6. Hales, C.A., Ahluwalia, B., \& Kazemi, H. Strength of pulmonary vascular response to regional alveolar hypoxia. J. Appl. Physiol. 38: 1083 (1975).

7. Enson, Y., Giuntini, G., Lewis, M.L., Morris, T.Q., Ferrez, M.I., \& Harvey, R.M. The influence of hydrogen jon concentration and hypoxia on the pulmonary circulation. J. Clin. Invest. 43: 1146 (1964).

8. RuDolpH, A.M. \& YUAN, S. Response of the pulmonary vasculature to hypoxia and $\mathrm{H}+$ ion concentration changes. J. Clin Invest. 45: 399 (1966).

9. Lxoyd, T.C. Influence of blood $\mathrm{pH}$ on hypoxic pulmonary vasoconstriction. J. Appl. Physiol. 21: 358 (1966).

I0. Barer, G.R., McCurrie, J.R., \& SHAw, J.W. Effect of changes in blood pH on the vascular resistance of the normal and hypoxic cat lung. Cardiovasc. Res. 5: 490 (1971).

11. Thilenius, $\mathrm{O} . \mathrm{B}$ \& \& Derenco, C. Effects of acutely indiced changes in arterial $\mathrm{pH}$ on pulmonary vascular resistance during normoxia and hypoxia in awake dogs, Clin. Sci. 42 : 277 (1972).

12. Sykes, M. K, Arnot, R.N., Jastrzebski, J., Gibis, J.M., Obdrzalek, J., \& Hurtic, J.B. Reduction of hypoxic pulmonary vasoconstriction during trichlorocthylene anaesthesia. J. Appl. Physiol. 39: 103 (1975)

13. Sykes, M.K., Huntig, J.B., Tait, A.R., \& Chakrabanti, M.K. Reduction of hypoxic pulmonary vasoconstriction during ether anaesthesia in the dog. Brit. J. Anaesth. Submitted for publication.

14. Sykes, M.K., Hurtig, J.B., Tait, A.R., \& Chakrayanti, M.K. Reduction of hypoxic pulmonary vasoconstriction in the dog during nitrous oxide administration. Brit. J. Anaesth. Submitted for publication.

15. Bjertnaes, L.J., Hauge, A., Nakken, K.F., \& Bredesen, J.E. Hypoxic pulmonary vasoconstriction: inhibition due to anaesthesia. Acta Physiol. Scand. 96: 283 (1976).

16. Sykes, M.K., Davies, D.M., Chakrabarti, M.K., LoH, L. The effects of halothane, trichloroethylene and ether on the hypoxic pressor response and pulmonary vascular resistance in the isolated perfused cat lung. Brit. J. Anaesth. 45: 655 (1973).

17. Nuns, J.F. Applied respiratory physiology, 1st ed. London: Butterworth (1969), p. 219 et seq. 
18. BeNunof, J.L. \& WAHRENBROCK, E.A. Blunted hypoxic pulmonary vasoconstriction by increased lung vascular pressures. J. Appl. Physiol. 38: 846 ( 1975).

19. Howeli, J.B.L., Permiut, S., Phoctor, D.F., \& Riley, R.L. Effects of inflation of the lung on different parts of the pulmonary vaseular bed. J. Appl. Physiol, 16: 71 (1961).

20. DALY, I. DE B. \& DALY, M. DE B. Sympathetic nerve control of pulnonary vascular resistance and impedance in isolated perfused lungs of the dog. J. Physiol. (Lond.) 234: $106 \mathrm{P}$ (1973).

21. DeForv, D.O. \& ECHT, R. The influence on pulmonary microvascular perfusion by the autonomic nervous system in intact dogs and cats. Microvasc. Res. 9: 357 (1975).

22. Porcelli, R.J. \& Bercofsky, E.H. Effect of $\mathrm{pH}$ on the pulmonary pressor response to humoral agents. J. Appl. Physiol. 31 : 679 (1971).

23. Kadowitz, P.J., Joiner, P.D., \& HrMan, A.L. Differential effects of phentolamine and bretylium on pulmonary vascular responses to norepinephrine and nerve stimulation. Proc. Soc. Exptl. Biol Med. 144: 172 (1973).

24. Baren, G.R. \& IICCurrie, J.R. Pulmonary vasomotor responses in the cat: the effect and interrelationships of drugs, hypoxia, and hypercapnia. Q. J. Exp. Plyysiol. 54: 156 (1969).

25. Poncelli, R.J. \& Bercorsky, E.H. Adrenergic receptors in pulmonary vasoconstrictor responses to gaseous and humoral agents. J. Appl. Physiol. $34: 483$ (1973).

26. Allison, P.R., DAly, I. DE B., \& WaAler, B.A. Bronchial circulation and pulmonary vasomotor nerve responses in isolated perfused lungs. J. Physiol. (Lond.) 15?: 462 (1961).

27. MALIK, A.B. \& KIDD, B.S.L. Independent effects of changes in $\mathrm{H}+$ and $\mathrm{CO}_{2}$ concentrations on hypoxic pulmonary vasoconstriction. J. Appl. Physiol. $34: 318$ (1973).

28. VILES, P.H. \& Shephend, J.T. Evidence for a dilator effect of carbon dioxide on the pulmonary vessels of the cat. Circ. Res. 22: 325 (1968).

29. BARER, G.R. \& SHAW, J.W, Pulmonary vasodilator and vasoconstrictor actions of carbon dioxide. J. Physiol. (Lond). 213; 633 (1971).

30. Bexdixex, H.H., Hedley-Whyte, J., \& LAver, M.B. Impaired oxygenation in surgical patients during general anaesthesia with controlled ventilation. New England J. Mled. 269: 991 (1963).

31. Nuns, J.F. Applied respiratory physiology, 1st ed. London: Butterworths (1969), p. 372 et seq. 